\title{
IL-33 and its increased serum levels as an alarmin for imminent pulmonary complications in polytraumatized patients
}

\author{
Gabriel Halát ${ }^{\text {(D) }}$, Thomas Haider, Michel Dedeyan, Thomas Heinz, Stefan Hajdu and Lukas L. Negrin
}

\begin{abstract}
Background: According to recently published findings, we hypothesized that serum interleukin-33 (IL-33) may qualify for predicting pulmonary complications in polytraumatized patients.

Methods: One hundred and thirty patients (age $\geq 18$ years, ISS $\geq 16$ ) were included in our prospective analysis after primary admission to our level I trauma center during the first post-traumatic hour. Serum samples immediately after admission and on day 2 after trauma were obtained and analyzed.

Results: Median initial IL-33 levels (in picograms per milliliter) were higher in polytrauma victims (1) with concomitant thoracic trauma [5.08 vs. 3.52; $p=0.036$ ], (2) sustaining parenchymal lung injury (PLI) [5.37 vs. 3.71; $p=0.027$ ], and (3) developing acute respiratory distress syndrome (ARDS) [6.19 vs. 4.48; $p=0.003]$, compared to the respective rest of the study group. The median initial IL-33 levels were higher in patients experiencing both PLI and ARDS compared to those sustaining PLI and not developing ARDS [6.99 vs. 4.69; $p=0.029]$. ROC statistics provided an AUC of $0.666(p=0.003)$ and a cut-off value of 4.77 (sensitivity, 71.8\%; specificity, 75.7\%) for predicting ARDS. Moreover, a higher initial median IL-33 level was revealed in the deceased compared to the survivors [12.25 vs. 4.72; $p=0.021]$. ROC statistics identified the initial level of IL-33 as a predictor of death with 11.19 as cut-off value (sensitivity, 80.0\%; specificity, 80.0\%; AUC $=0.805 ; p=0.021$ ).

Conclusions: Following tissue damage, IL-33 is abundantly released in the serum of polytraumatized patients immediately after their injuries occurred. As initial IL-33 levels were particularly high in individuals experiencing both PLI and ARDS, IL-33 release after trauma seems to be involved in the promotion of ARDS and might serve already at admission as a solid indicator of impending death in polytraumatized patients.
\end{abstract}

Keywords: IL-33, Alarmin, Polytrauma, ARDS, Biomarker, Thoracic injury

\section{Background}

In polytrauma care, the timing of definitive surgical treatment of major skeletal injuries is crucial for morbidity and mortality. In general, there are two treatment strategies for fracture care in polytraumatized patients [1]. Early total care involves definitive surgical stabilization of all long bone fractures during the early phase of treatment, whereas damage control orthopedics suggests temporary external fracture fixation with secondary definitive osteosynthesis after stabilization of the patient's physiological and immunological status at the intensive care unit (ICU). Polytrauma victims with concomitant severe chest trauma

\footnotetext{
* Correspondence: gabriel.halat@meduniwien.ac.at University Department of Orthopedics and Trauma-Surgery, Medical University of Vienna, Währinger Gürtel 18-20, 1090 Vienna, Austria
}

are at high risk of developing an acute respiratory distress syndrome (ARDS) and/or pneumonia. As these patients are considered especially vulnerable to a sustained inflammatory response from immediate surgical intervention, damage control orthopedics seems to be their treatment of choice as it reduces the risk for complications and adverse outcome related to the surgical second hit [2]. However, pulmonary complications may develop while waiting for secondary surgery, potentially compromising definitive osteosynthesis, and thus the best possible outcome. In consequence, the choice of fracture treatment poses a serious challenge to trauma surgeons. Providing decisionmaking tools concerning this matter was the impetus of our biomarker research.

(c) The Author(s). 2019 Open Access This article is distributed under the terms of the Creative Commons Attribution 4.0 International License (http://creativecommons.org/licenses/by/4.0/), which permits unrestricted use, distribution, and reproduction in any medium, provided you give appropriate credit to the original author(s) and the source, provide a link to the Creative Commons license, and indicate if changes were made. The Creative Commons Public Domain Dedication waiver (http://creativecommons.org/publicdomain/zero/1.0/) applies to the data made available in this article, unless otherwise stated. 
Interleukin-33 (IL-33) is the most recent addition to the IL-1 family, discovered in 2005 [3]. Full-length IL-33 (IL33FL) is composed of a nuclear domain, which is critical for nuclear localization and chromatin association, a connecting central part, and an IL-1-like cytokine domain, which is essential for activation of the immune system [4,5]. It is constitutively expressed at high basal levels and stored within the nuclear compartment of structural cell types, most notably by vascular endothelial cells and epithelial cells of human barrier tissues [3, 4]. According to the current knowledge, passive release and active secretion make nuclear IL-33FL available to the extracellular space $[4,5]$, where it is processed into shorter mature forms [6]. They contain an intact IL-1-like cytokine domain and exhibit an up to 30 times greater biological activity than IL-33FL, depending on the size of the protein $[6,7]$ and are inactivated within $2 \mathrm{~h}$ in the extracellular environment $[4,8]$. The relevant mechanisms are presented in Fig. 1 [5, 6, 9-13].

IL-33 has been identified as an endogenous alarm signal (alarmin) $[11,14]$ to alert various types of immune cells to tissue damage or stress $[3,15,16]$. Both full-length and mature IL-33 (hereafter collectively referred to as IL33) act specifically through the receptor ST2L, a transmembrane, long isoform of suppression of tumorigenicity 2 (ST2) [17, 18], whose expression is restricted to the surface of Th2 cells and mast cells [18]. Whereas ST2L mediates the inflammatory effect of IL-33, sST2, a short, soluble isoform, which is mainly secreted by fibroblasts [19], exerts immunosuppressive activity by acting as a decoy receptor that prevents the interaction of ST2L with IL-33 [20] or shows a direct anti-inflammatory impact [21].

To the present day, only a few studies have been published on the role of IL-33 in ARDS. Using a mouse model, $\mathrm{Fu}$ and coworkers identified IL-33 as an important factor involved in the progression of pulmonary inflammation in ARDS [22]. Lin and coworkers detected higher serum levels of IL-33 in 14 patients suffering from ARDS compared to healthy controls [23].

The objective of our study was to analyze serum IL-33 levels in severely injured patients and investigate its potential role as an alarmin in polytrauma care. Considering previously published data on IL-33, we were further interested whether IL-33 is involved in pulmonary complications commonly observed in this patient collective.

\section{Methods}

From 2011 to 2015, after approval by the Local Ethics Committee of the Medical University of Vienna (project number 368/2011), we included 130 polytrauma victims [Injury Severity Score (ISS) $\geq 16$; age $\geq 18$ years] into our study population. All of them were directly admitted to our level I trauma center within $1 \mathrm{~h}$ after trauma and were transferred to the intensive care unit after initial treatment due to a compromised medical condition surviving for at least $24 \mathrm{~h}$. Burn victims and patients with known malignancies or chronic inflammatory lung diseases were excluded.

One additional separating gel tube (Vacuette ${ }^{\oplus} 4 \mathrm{~mL}$; Greiner Bio-One International) for biomarker level assessment was collected during routine blood work at admission and on day $2(24-48 \mathrm{~h})$ after trauma. These samples were immediately centrifuged at $3000 \times g$ for 15 $\mathrm{min}$ at room temperature. Sera were removed and stored at $-80{ }^{\circ} \mathrm{C}$ until further assessment. Analysis was performed only in patients, where informed consent could be obtained from the patient. In deceased patients, informed consent was obtained either from the patient prior to death or the closest relative, or from the patient's legal representative.

Initially, the collected samples were used for the measurement of five biomarker levels [24]. Remaining serum aliquots were analyzed for this post hoc study. Serum levels of IL-33 were measured using an enzyme-linked

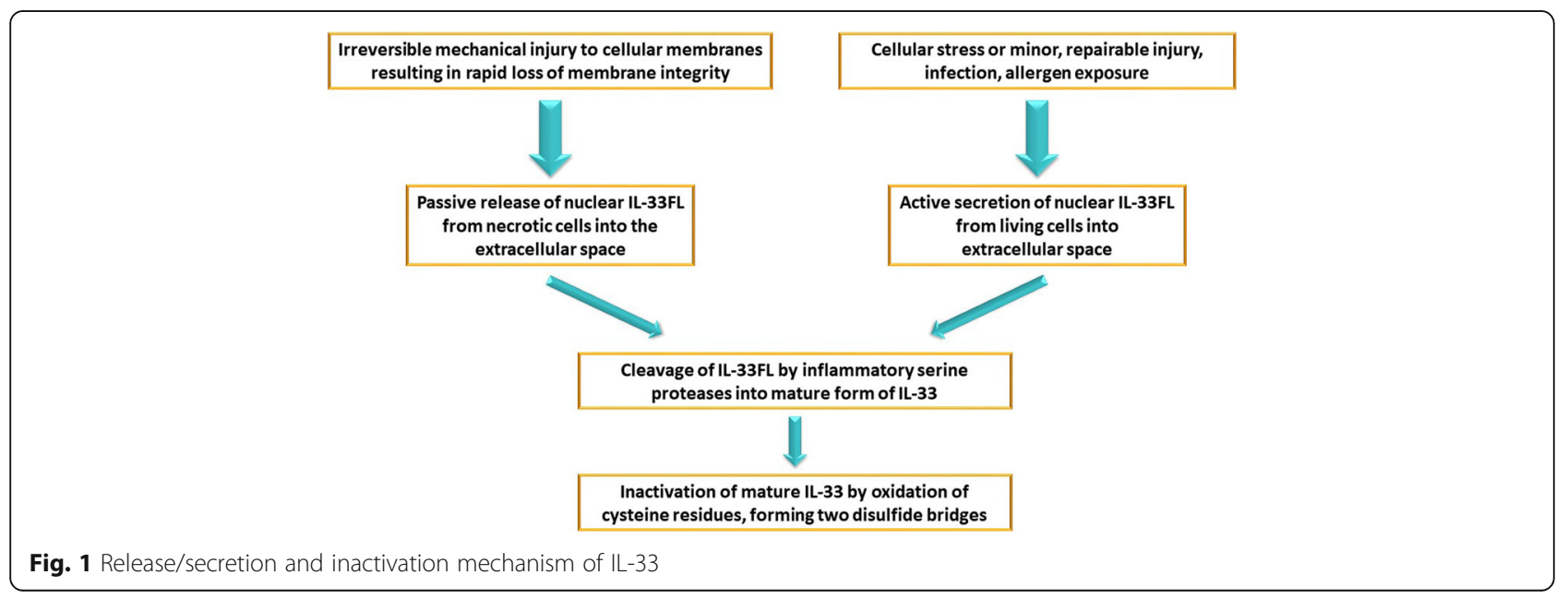


immunosorbent assay (Human IL-33 ELISA Kit, Promokine PK-EL-62958 Minneapolis, MN, USA) according to the manufacturer's instructions. All samples were evaluated in triplets and the mean values were calculated. To obtain a reference value, only one blood sample was taken from 10 age-matched, healthy individuals.

Parenchymal lung injury (PLI) was detected by computed tomography scans performed at admission. ARDS was diagnosed according to the Berlin definition [25], which is based on clinical and radiographic data. Pneumonia was identified by a temperature deviation from normal $\left(>38^{\circ} \mathrm{C}\right.$ or $<35.5^{\circ} \mathrm{C}$ ), either leucocytosis (white cell count $>10,000 / \mathrm{mm}^{3}$ or $>10 \%$ immature forms) or leucopenia (white cell count $<4,000 / \mathrm{mm}^{3}$ ); a macroscopically purulent sputum, the presence of a newly developed cough, dyspnea, and/or tachypnea (in the case of spontaneous breathing patients); and a new or changing infiltrate on chest radiographs.

Statistical analysis was conducted using IBM SPSS Statistics (Version 24). Due to skew distributions, parameters are presented as median and interquartile range in round brackets. Continuous variables were matched using the Mann-Whitney-Wilcoxon rank-sum test (for unrelated samples) and the Wilcoxon signed-rank test (for related samples). Categorical data were analyzed by means of the chi-square test. Receiver operating characteristic (ROC) curves and areas under the curve (AUC) were computed, the latter presented with a 95\% confidence interval $(\mathrm{CI})$. Cut-off values were determined by the maximum sum of sensitivity and specificity [26]. For correlations, the Spearman rank coefficient $(\rho)$ was calculated. In general, the threshold of significance was set at $p=0.05$.

\section{Results}

Demographic data of our polytraumatized patients are presented in Table 1. ARDS onset was observed within 2 days after admission in 32 of the affected 42 patients, whereas first signs of pneumonia were clearly distinct on day 4 after admission. This was even the case in patients with primary onset of ARDS. In all individuals suffering from pneumonia and ARDS, pneumonia was diagnosed after the occurrence of ARDS. During hospitalization, five patients died after a median time period of 3 days (range, 1-24); causes of death were ARDS in three cases and one case of multiorgan failure and traumatic brain injury, respectively.

IL-33 levels assessed at admission and on day 2 after trauma are presented in Table 2.

In all of our patients, initial IL-33 levels were higher than the reference value of $0.25 \mathrm{pg} / \mathrm{mL}$ provided by our healthy controls. In our study group and all respective subgroups median IL-33 levels declined from admission to day 2 after trauma. Of interest, only in 15 individuals (11.5\%) an increase in IL-33 levels could be observed.
Table 1 Demographic data

\begin{tabular}{ll}
\hline & Median/number \\
\hline Age & $39(26-55)$ years \\
Male/female & $90 / 40$ \\
ISS & $30(22-41)$ \\
Thoracic trauma & 118 \\
PLI & 108 \\
ARDS & 42 \\
Pneumonia & 41 \\
ARDS and pneumonia & 27 \\
ARDS no pneumonia & 15 \\
Pneumonia no ARDS & 14 \\
No ARDS no pneumonia & 74 \\
C-reactive protein day 0 & $0.16(0.05-0.47) \mathrm{g} / \mathrm{L}$ \\
C-reactive protein day 2 & $6.26(2.38-10.19) \mathrm{g} / \mathrm{L}$ \\
Leukocyte count day 0 & $12.22(9.39-16.32) \mathrm{g} / \mathrm{L}$ \\
Leukocyte count day 2 & $9.05(7.07-10.76) \mathrm{g} / \mathrm{L}$ \\
Hemoglobin concentration day 0 & $11.70(9.48-13.30) \mathrm{g} / \mathrm{L}$ \\
Hemoglobin concentration day 2 & $9.90(8.80-11.40) \mathrm{g} / \mathrm{L}$ \\
\hline
\end{tabular}

Comparing patients with an increase and decrease of IL33 levels within the first two post-traumatic days revealed solely a higher leukocyte count in the former group [15.99 $(10.48-19.34)$ g/L vs. $11.86(8.92-15.40)$ g/L]. Furthermore, a strong correlation $(\rho=0.721 ; p<0.0001)$ between the initial and the day 2 levels of IL-33 was observed.

In order to identify the individuals presenting with the highest IL-33 levels at admission, we subdivided our polytraumatized patient collective according to the parameters PLI and ARDS, resulting in four groups: "-PLI-ARDS" combing patients without PLI and ARDS, "-PLI+ARDS" denoting those without PLI and suffering from ARDS as well as "+PLI-ARDS," and "+PLI+ARDS" including those sustaining PLI and not developing/developing ARDS. Significant differences in AIS $_{\text {Thorax }}$, ISS and the development of pneumonia are presented in Table 3.

As the three individuals forming the "-PLI+ARDS" did not show any pathologic changes in their thoracic CT scans, they suffered from indirect ARDS. Of interest, no statistically significant differences in initial IL-33 levels between the "-PLI+ARDS" and the "PLI+ARDS" group could be calculated $[2.64(2.35-2.64) \mathrm{pg} / \mathrm{mL}$ vs. 6.99 $(4.56-12.17) \mathrm{pg} / \mathrm{mL} ; p=0.172]$.

Figure 2 graphically displays the distribution of initial IL-33 levels in the four subgroups. Significant differences could be revealed solely between the "-PLI-ARDS" and the "+PLI+ARDS" group $(p=0.009)$ as well as between the "+PLI-ARDS" and the "+PLI+ARDS" group $(p=0.029)$.

The distribution of IL-33 levels assessed in the four subgroups on day 2 after trauma is presented in Fig. 3. 
Table 2 IL-33 levels

\begin{tabular}{|c|c|c|c|c|}
\hline & & $\begin{array}{l}\text { IL-33 initial } \\
(\mathrm{pg} / \mathrm{mL})\end{array}$ & $\begin{array}{l}\text { IL-33 day } 2 \\
\text { (pg/mL) }\end{array}$ & $p$ value \\
\hline Total & & $4.81(3.39-9.20)$ & $3.45(2.07-5.02)$ & $<0.0001$ \\
\hline \multirow[t]{3}{*}{ Gender } & Male & $4.99(2.97-8.83)$ & $3.51(2.00-5.04)$ & $<0.0001$ \\
\hline & Female & $4.72(3.71-9.72)$ & $3.30(2.12-4.93)$ & $<0.0001$ \\
\hline & & $p=0.779$ & $p=0.911$ & \\
\hline \multirow{3}{*}{$\begin{array}{l}\text { Thoracic } \\
\text { trauma }\end{array}$} & Yes & $5.08(3.48-9.61)$ & $3.51(2.02-5.05)$ & $<0.0001$ \\
\hline & No & $3.52(2.51-4.70)$ & $2.59(2.17-4.34)$ & 0.012 \\
\hline & & $p=0.036$ & $p=0.545$ & \\
\hline \multirow[t]{3}{*}{ PLI } & Yes & $5.37(3.48-9.71)$ & $3.58(2.11-5.03)$ & $<0.0001$ \\
\hline & No & $3.71(2.43-5.17)$ & $2.33(1.89-3.87)$ & 0.001 \\
\hline & & $p=0.027$ & $p=0.083$ & \\
\hline \multirow[t]{3}{*}{ ARDS } & Yes & $6.19(4.42-11.90)$ & $4.70(2.79-6.36)$ & $<0.0001$ \\
\hline & No & $4.48(2.79-6.33)$ & $2.79(1.64-4.40)$ & $<0.0001$ \\
\hline & & $p=0.003$ & $p=0.001$ & \\
\hline \multirow[t]{3}{*}{ Pneumonia } & Yes & $5.41(3.83-10.81)$ & $3.94(2.49-5.60)$ & $<0.0001$ \\
\hline & No & $4.58(3.07-7.90)$ & $3.04(1.72-4.74)$ & $<0.0001$ \\
\hline & & $p=0.106$ & $p=0.219$ & \\
\hline \multirow[t]{3}{*}{ Fatality } & Yes & $12.25(7.58-23.68)$ & $3.53(2.96-15.48)$ & 0.068 \\
\hline & No & $4.72(3.27-8.25)$ & $3.42(2.92-5.01)$ & $<0.0001$ \\
\hline & & $p=0.021$ & $p=0.430$ & \\
\hline
\end{tabular}

Significant differences between the "-PLI-ARDS" and the "+PLI+ARDS" group $(p=0.023)$ as well as between the "+PLI-ARDS" and the "+PLI+ARDS" $(p=0.039)$ were detected.

Due to the fact that ARDS was diagnosed in $76.2 \%$ of the affected patients up to day 2, solely initial IL-33 levels may serve as a predictor of ARDS in clinical practice. The corresponding ROC curve is shown in Fig. 4, providing an AUC of 0.666 (95\% CI, 0.561$0.771 ; p=0.003)$ and a cut-off value of $4.77 \mathrm{pg} / \mathrm{mL}$ (sensitivity, 71.8\%; specificity, 75.7\%).

As Table 2 shows, initial IL-33 levels were 2.6 times higher in deceased patients compared to survivors with their distributions being displayed in Fig. 5. However, no significant difference could be revealed on day 2 in this regard.

ROC statistics identified the initial IL-33 level as a predictor of death with an AUC of 0.805 (95\% CI, 0.596-1.000; $p=0.021$ ) and a cut-off value of $11.19 \mathrm{pg} / \mathrm{mL}$ (sensitivity, $80.0 \%$; specificity, $80.0 \%$ ). The respective ROC curve is presented in Fig. 6.

Finally, we focused on correlations between the initial and the day 2 levels of IL-33 and all continuous parameters assessed in this study, including initial lactate and C-reactive protein levels. Initial IL-33 levels were solely significantly correlated to ISS $(\rho=0.274 ; p<0.01)$, duration of mechanical ventilation $(\rho=0.298 ; p<0.01)$, and hospitalization period $(\rho=0.212 ; p<0.05)$, whereas day 2 levels of IL-33 were only significantly correlated to the duration of mechanical ventilation $(\rho=0.365 ; p<0.01)$.

\section{Discussion}

To our knowledge, we are the first to evaluate IL-33 levels as a potential biomarker in polytraumatized patients with respect to its predictive value on secondary pathophysiological conditions. Our prospective study revealed a generally sharp increase in IL-33 levels after polytrauma. Both initial and day 2 levels of IL-33 were significantly higher in polytraumatized patients sustaining PLI and developing ARDS compared to those only sustaining PLI, and, clinically most relevant, initial IL-33 levels higher than $11.19 \mathrm{pg} / \mathrm{mL}$ were identified to indicate a high risk of death following polytrauma.

PLI is characterized by micro-hemorrhages caused by alveolar damage and alveolar strain that occur at traumatic separation of alveoli from airway structures and blood vessels created by shear stress or overdistension [27]. As the internal surface of the alveoli is lined by the epithelium [28], local regions of high mechanical stress are likely to cause direct necrosis of alveolar epithelial cells [29]. The interaction of PLI-induced tissue injury and inflammatory response results in an increase of cell

Table 3 Subgroup characteristics

\begin{tabular}{|c|c|c|c|c|c|c|}
\hline & & \multicolumn{4}{|l|}{ Groups } & \multirow[b]{2}{*}{$p$ value } \\
\hline & & -PLI-ARDS & -PLI+ARDS & + PLI-ARDS & + PLI+ARDS & \\
\hline \multirow[t]{6}{*}{$\overline{\text { AIS }_{\text {Thorax }}}$} & 0 & 9 & 3 & 0 & 0 & \multirow[t]{6}{*}{$<0.0001$} \\
\hline & 1 & 3 & 0 & 0 & 0 & \\
\hline & 2 & 4 & 0 & 5 & 5 & \\
\hline & 3 & 3 & 0 & 33 & 4 & \\
\hline & 4 & 0 & 0 & 21 & 14 & \\
\hline & 5 & 0 & 0 & 10 & 16 & \\
\hline \multirow[t]{2}{*}{ Pneumonia } & Yes & 4 & 3 & 10 & 24 & \multirow[t]{2}{*}{$<0.0001$} \\
\hline & No & 15 & 0 & 59 & 15 & \\
\hline ISS & & $22(17-34)^{*}$ & $29(26-34)$ & $29(22-38)$ & $36(26-43)^{*}$ & $0.003^{*}$ \\
\hline
\end{tabular}

*Tag the two groups with significantly different ISS values 


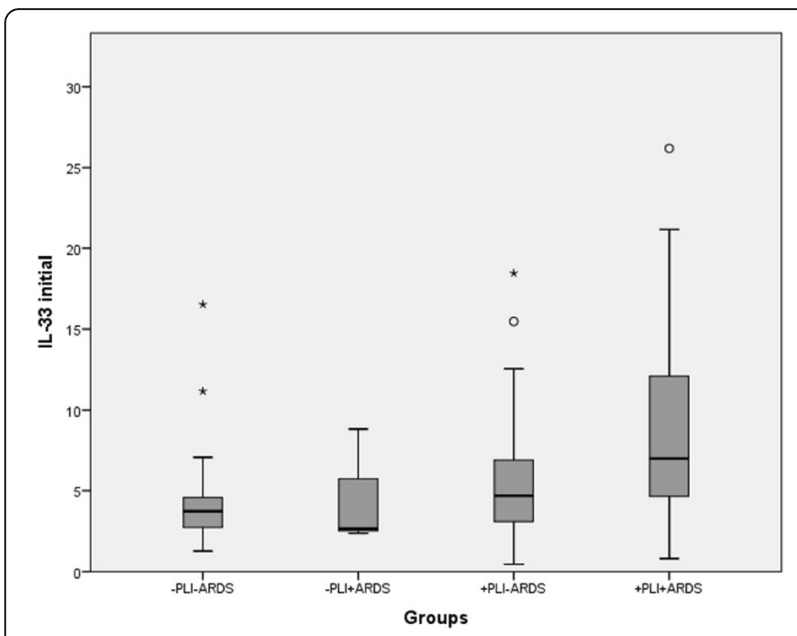

Fig. 2 Distribution of initial IL-33 levels according to group assignment

membrane permeability, protein-rich alveolar edema, and increased epithelial cell necrosis [30, 31], all of which potentially promote the development of direct ARDS [32]. Whereas the latter is caused by direct injury to the lung epithelium, in indirect ARDS, the vascular endothelium of the lung is diffusely damaged by circulating inflammatory mediators released in the setting of systemic disorders [33].

Meeting the expectations of an alarmin in the event of a barrier breach, IL-33 was abundantly detected in the serum of polytrauma victims already at admission. The lung was identified as not the only, but a potential relevant source of IL-33 as its levels were significantly higher in individuals with concomitant thoracic trauma. Due to the fact that $91.5 \%$ of them sustained PLI, our study group was subdivided according to its presence. Not surprisingly, initial IL-33 levels were higher in the PLI group. As initial IL-33 levels were also higher in the

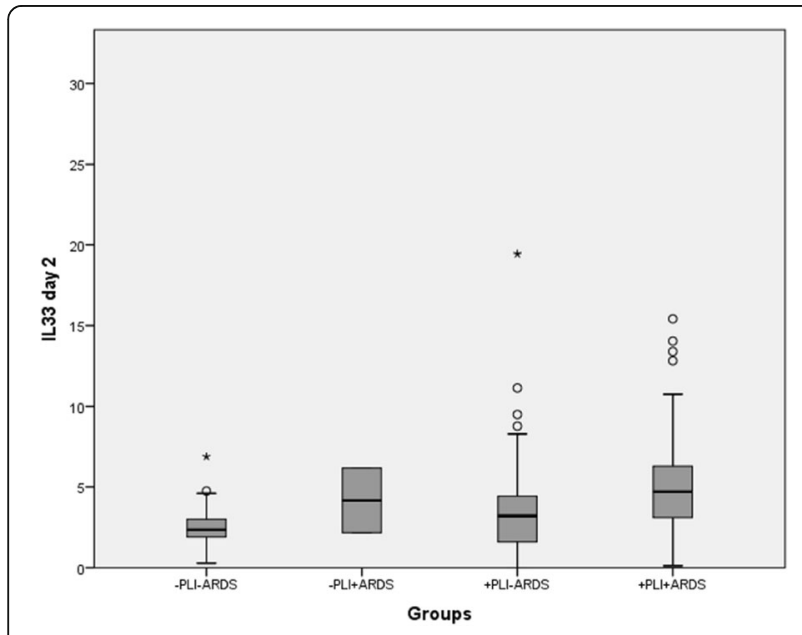

Fig. 3 Distribution of IL-33 day 2 levels according to group assignment

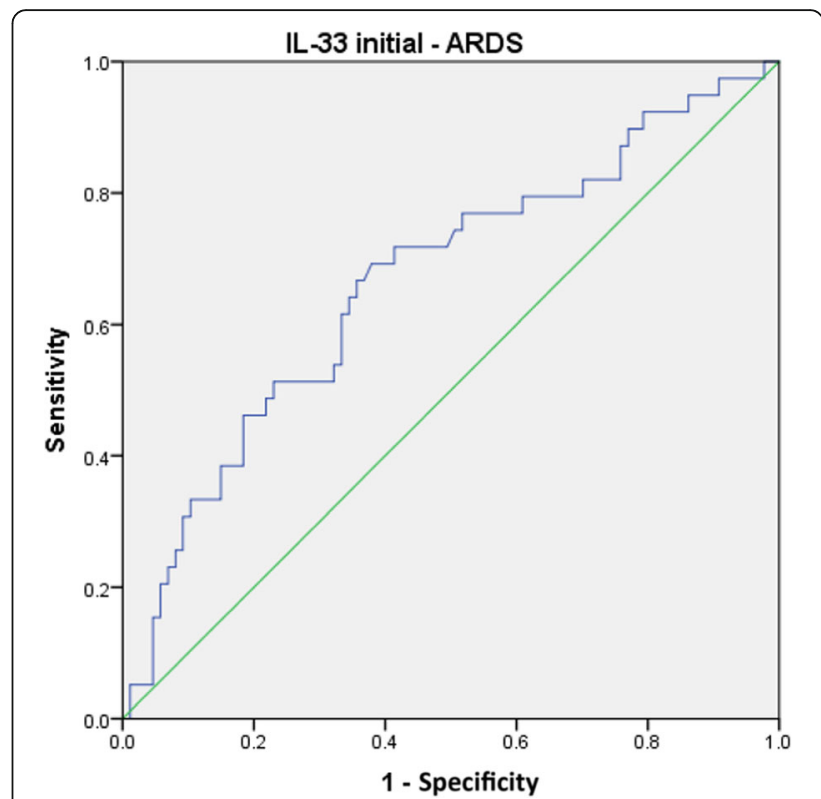

Fig. 4 ROC curve for the initial IL-33 level and ARDS

ARDS group compared to the non-ARDS group, we subdivided our patients according to the parameters "presence of PLI" and "development of ARDS," revealing a significant difference in initial IL-33 levels between the "+PLI-ARDS" group and the "+PLI+ARDS" group. Justified by its abundant storage in the nuclei of parenchymal cells, the major proportion of IL-33 in our opinion was most likely released during necrosis. Because extensive epithelial necrosis is a prominent feature of direct ARDS in the current state of knowledge [32], the high levels of initial IL-33 in the "+PLI+ARDS" group might mainly originate from irreparably, mechanically damaged epithelial cells of the lung. Moreover, we hypothesize that IL-33 release may be an initial event in the inflammatory

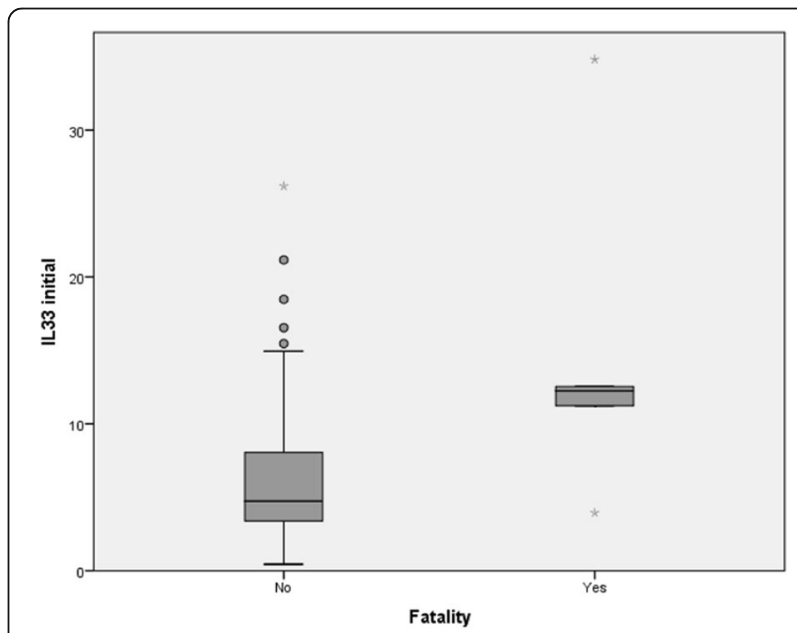

Fig. 5 Distribution of initial IL-33 in survivors and deceased 


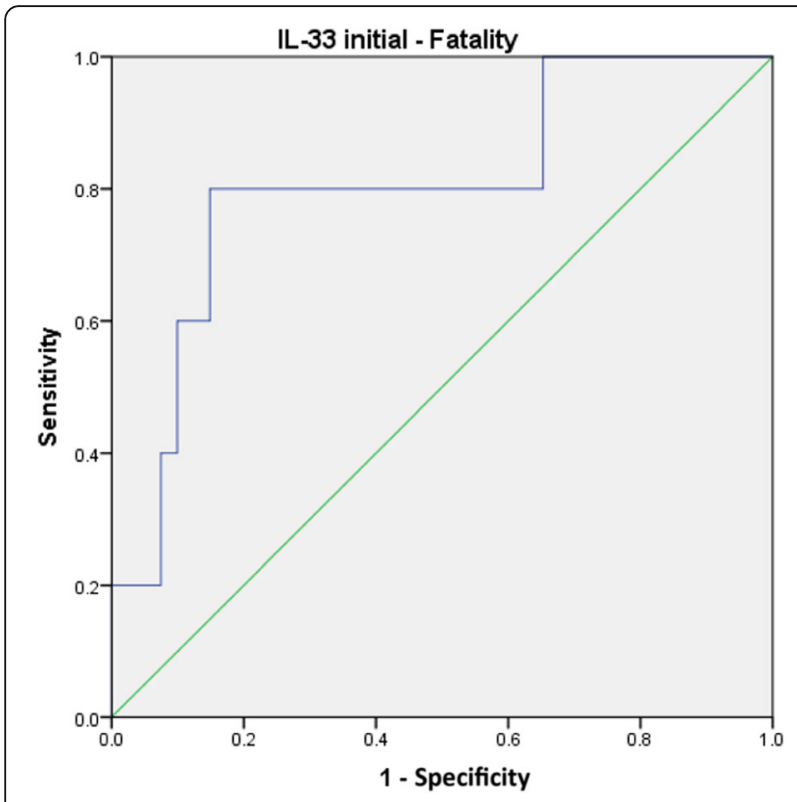

Fig. 6 ROC curve for the initial IL-33 level and fatality

process of direct ARDS. As the pathogenesis of indirect ARDS starts with endothelial damage [33], differences in initial IL-33 levels between patients developing direct and indirect ARDS have to be expected. Whereas Lin and coworkers revealed significantly higher IL-33 levels in patients suffering from direct ARDS compared to those with indirect ARDS $(p<0.01)$ [23], our marked difference $(6.99 \mathrm{pg} / \mathrm{mL}$ vs. $2.84 \mathrm{pg} / \mathrm{mL})$ did not reach statistical significance, probably due to the group size mismatch.

According to ROC statistics IL-33 levels, which are assessed at admission and exceed the cut-off value of $4.77 \mathrm{pg} / \mathrm{mL}$, they accurately identify $71.8 \%$ of polytraumatized patients developing ARDS, whereas $75.7 \%$ of the individuals with an initial IL-33 level lower than $4.77 \mathrm{pg} / \mathrm{mL}$ are expected not to suffer from ARDS. Unfortunately, our cut-off value is not statically robust enough to identify initial IL-33 as a reliable predictor of ARDS; nevertheless, it might yield distinct information for the clinician. IL-33 release is not lung-specific; it is also expressed at epithelial surfaces in the skin, stomach, intestine, salivary gland, vagina, and lung [34]. Moreover, transient release of endogenous IL-33 has been reported after mechanical skin injury [35] and, because of its widespread expression in the nuclei of endothelial cells from blood vessels along the vascular tree, IL-33 can be found in almost all human organs [3]. Due to the multitude of possible sources of IL-33 in the human body, the high initial IL-33 levels may indicate alarming rates of necrotic cell death in several vital organs, thus alerting a compromised patient condition at admission that necessitates damage control orthopedics. Early total care, associated with a prolonged surgery time, may induce an even more compromising secondary impact on the injured organism. However, using our cut-off value of $11.19 \mathrm{pg} / \mathrm{mL}$, we were able to identify a lethal outcome in polytraumatized patients with an accuracy of $80 \%$, supporting our hypothesis.

As expected of an alarmin, IL-33 levels declined in $96.2 \%$ of our patients within the first two post-traumatic days. The rapid inactivation of the released protein, which limits its range and duration of action, in combination with an increasingly smaller release from necrotic cells might be the reason for this finding.

\section{Conclusions}

As serum IL-33 levels increased in all of our patients immediately after they had sustained multiple injuries, IL33 can be considered as an alarmin in the response to polytrauma, indicating the amount of damaged structural cells by mechanical impact. Particularly high initial IL-33 levels were detected in individuals experiencing both PLI and ARDS, probably due to the highest amount of necrotic epithelial lung cells. Although we were able to identify IL-33 release after trauma as an initial event in the inflammatory process of direct ARDS, initial IL33 levels did not provide sufficient statistical reliability as a predictor of ARDS in polytrauma care. However, considering our findings, we advocate the option of a damage control approach when elevated IL33 serum levels are encountered in the acute setting of polytrauma treatment. Furthermore, initial IL-33 levels might serve as an indicator of impending death in polytraumatized patients already at admission. Being aware of the fact that our cut-off value can only be considered as an indicative parameter due to the small number of fatalities in our study group, we recommend large multi-center trials in order to provide a reliable cut-off value.

\section{Abbreviations}

IL-33: Interleukin-33; sST2: Soluble suppression of tumorgenicity-2; PLI: Parenchymal lung injury; ARDS: Acute respiratory distress syndrome; ISS: Injury Severity Score; AIS: Abbreviated Injury Scale

\section{Acknowledgements}

Not applicable

\section{Authors' contributions}

$\mathrm{GH}$ wrote the main manuscript text and was involved in blood serum acquisition and patient data collection. LLN contributed to the manuscript compilation in a preeminent manner and performed the statistical analysis of the data. THa and MD were involved in blood serum acquisition, as well as in patient data collection. THe and SH proofread the manuscript and contributed substantially to the study design. LLN, THa, THe, SH, and MD proofread the manuscript. All listed authors revised the final manuscript and gave their approval for submission. 


\section{Availability of data and materials}

The datasets used and/or analyzed during the current study are available from the corresponding author on reasonable request.

\section{Ethics approval and consent to participate}

The study was approved by the Local Ethics Committee of the Medical University of Vienna (project number 368/2011).

Informed consent was obtained from all included surviving patients. In deceased patients, informed consent was obtained either from the patient prior to death or the closest relative, or from the patient's legal representative.

No individual participant's data were used in this study.

\section{Consent for publication}

Not applicable.

\section{Competing interests}

The authors declare that they have no competing interests.

Received: 28 May 2019 Accepted: 10 July 2019

Published online: 19 July 2019

\section{References}

1. Nicola R. Early total care versus damage control: current concepts in the orthopedic care of polytrauma patients. ISRN Orthop. 2013:2013:329452.

2. Mommsen P, Krettek C, Hildebrand F. Chest trauma: classification and influence on the general management. In: Pape HC, Sanders R, Borrelli JJ, editors. The poly-traumatized patient with fractures: a multi-disciplinary approach. Heidelberg Dordrecht London New York: Springer; 2011.

3. Moussion C, Ortega N, Girard JP. The IL-1-like cytokine IL-33 is constitutively expressed in the nucleus of endothelial cells and epithelial cells in vivo: a novel 'alarmin'? PLoS One. 2008;3(10):e3331.

4. Cayrol C, Girard JP. Interleukin-33 (IL-33): a nuclear cytokine from the IL-1 family. Immunol Rev. 2018;281(1):154-68.

5. Drake LY, Kita H. IL-33: biological properties, functions, and roles in airway disease. Immunol Rev. 2017:278(1):173-84.

6. Lefrançais E, Roga S, Gautier V, Gonzalez-de-Peredo A, Monsarrat B, Girard $J P$, et al. IL-33 is processed into mature bioactive forms by neutrophil elastase and cathepsin G. Proc Natl Acad Sci U S A. 2012;109(5):1673-8.

7. Morita H, Nakae S, Saito H, Matsumoto K. IL-33 in clinical practice: size matters? J Allergy Clin Immunol. 2017;140(2):381-3.

8. Cohen ES, Scott IC, Majithiya JB, Rapley L, Kemp BP, England E, et al. Oxidation of the alarmin IL-33 regulates ST2-dependent inflammation. Nat Commun. 2015;6:8327.

9. Mattson MP, Bazan NG. Apoptosis and necrosis. In: Brady ST, Siegel GJ, Albers RW, Price DL, editors. Basic neurochemistry: principles of molecular, cellular, and medical neurobiology: Elesivier; 2012. p. 663-76.

10. Proskuryakov SY, Konoplyannikov AG, Gabai VL. Necrosis: a specific form of programmed cell death? Exp Cell Res. 2003;283(1):1-16.

11. Lüthi AU, Cullen SP, McNeela EA, Duriez PJ, Afonina IS, Sheridan C, et al. Suppression of interleukin-33 bioactivity through proteolysis by apoptotic caspases. Immunity. 2009;31(1):84-98.

12. Kakkar R, Hei H, Dobner S, Lee RT. Interleukin 33 as a mechanically responsive cytokine secreted by living cells. J Biol Chem. 2012;287(9):6941-8.

13. Liew FY, Girard JP, Turnquist HR. Interleukin-33 in health and disease. Nat Rev Immunol. 2016;16(11):676-89.

14. Cayrol C, Girard JP. IL-33: an alarmin cytokine with crucial roles in innate immunity, inflammation and allergy. Curr Opin Immunol. 2014:31:31-7.

15. Cayrol C, Girard JP. The IL-1-like cytokine IL-33 is inactivated after maturation by caspase-1. Proc Natl Acad Sci U S A. 2009:106(22):9021-6.

16. Liew FY, Pitman N, McInnes IB. Disease-associated functions of IL-33: the new kid in the IL-1 family. Nature reviews Immunology. 2010;10(2):103-10.

17. Trajkovic V, Sweet MJ, Xu D. T1/ST2--an IL-1 receptor-like modulator of immune responses. Cytokine Growth Factor Rev. 2004;15(2-3):87-95.

18. Schmitz J, Owyang A, Oldham E, Song Y, Murphy E, McClanahan TK, et al. IL-33, an interleukin-1-like cytokine that signals via the IL-1 receptor-related protein ST2 and induces T helper type 2-associated cytokines. Immunity. 2005;23(5):479-90

19. Bergers $G$, Reikerstorfer A, Braselmann S, Graninger P, Busslinger M. Alternative promoter usage of the Fos-responsive gene Fit-1 generates
mRNA isoforms coding for either secreted or membrane-bound proteins related to the IL-1 receptor. EMBO J. 1994:13(5):1176-88.

20. Hong YS, Moon SJ, Joo YB, Jeon CH, Cho ML, Ju JH, et al. Measurement of interleukin-33 (IL-33) and IL-33 receptors (SST2 and ST2L) in patients with rheumatoid arthritis. J Korean Med Sci. 2011;26(9):1132-9.

21. Travers J, Rochman M, Miracle CE, Habel JE, Brusilovsky M, Caldwell JM, et al Chromatin regulates IL-33 release and extracellular cytokine activity. Nat Commun. 2018;9(1):3244

22. Fu J, Lin SH, Wang CJ, Li SY, Feng XY, Liu Q, et al. HMGB1 regulates IL-33 expression in acute respiratory distress syndrome. Int Immunopharmacol. 2016:38:267-74.

23. Lin SH, Fu J, Wang CJ, Gao F, Feng XY, Liu Q, et al. Inflammation elevated IL-33 originating from the lung mediates inflammation in acute lung injury. Clin Immunol. 2016;173:32-43.

24. Negrin LL, Halat G, Prosch H, Hüpfl M, Hajdu S, Heinz T. Soluble receptor for advanced glycation end products quantifies lung injury in polytraumatized patients. Ann Thorac Surg. 2017;103(5):1587-93.

25. Definition Task Force ARDS, Ranieri VM, Rubenfeld GD, Thompson BT, Ferguson ND, Caldwell $\mathrm{E}_{\text {, et }}$ al. Acute respiratory distress syndrome: the Berlin definition. JAMA. 2012;307(23):2526-33.

26. Youden WJ. Index for rating diagnostic tests. Cancer. 1950;3(1):32-5.

27. Sattler S, Maier RV. Pulmonary contusion. In: Karmy-Jones R, Nathens A, Stern EJ, editors. Thoracic trauma and critical care Berlin: Springer; 2002. p. $159-60$ and $235-43$.

28. Suki B, Stamenović D, Hubmayr R. Lung parenchymal mechanics. Compr Physiol. 2011:1(3):1317-51.

29. Martin TR. Interactions between mechanical and biological processes in acute lung injury. Proc Am Thorac Soc. 2008;5(3):291-6.

30. Raghavendran K, Notter RH, Davidson BA, Helinski JD, Kunkel SL, Knight PR. Lung contusion: inflammatory mechanisms and interaction with other injuries. Shock. 2009;32(2):122-30.

31. Ware LB, Matthay MA. The acute respiratory distress syndrome. N Engl J Med. 2000:342(18):1334-49.

32. Herrero R, Sanchez G, Lorente JA. New insights into the mechanisms of pulmonary edema in acute lung injury. Ann Transl Med. 2018:6(2):32.

33. Shaver CM, Bastarache JA. Clinical and biological heterogeneity in acute respiratory distress syndrome: direct versus indirect lung injury. Clin Chest Med. 2014;35(4):639-53.

34. Molofsky AB, Savage AK, Locksley RM. Interleukin-33 in tissue homeostasis, injury, and inflammation. Immunity. 2015;42(6):1005-19.

35. Galand C, Leyva-Castillo JM, Yoon J, Han A, Lee MS, McKenzie ANJ, et al. IL33 promotes food anaphylaxis in epicutaneously sensitized mice by targeting mast cells. J Allergy Clin Immunol. 2016;138(5):1356-66.

\section{Publisher's Note}

Springer Nature remains neutral with regard to jurisdictional claims in published maps and institutional affiliations.

Ready to submit your research? Choose BMC and benefit from:

- fast, convenient online submission

- thorough peer review by experienced researchers in your field

- rapid publication on acceptance

- support for research data, including large and complex data types

- gold Open Access which fosters wider collaboration and increased citations

- maximum visibility for your research: over $100 \mathrm{M}$ website views per year

At BMC, research is always in progress.

Learn more biomedcentral.com/submissions 